\title{
Commentary
}

\section{The Body-Image Concept Analysis of Youth and Adolescent}

\author{
Fikir Alebachew $^{1}$, Melaku Ashagrie ${ }^{2}$ \\ ${ }^{1}$ Department of Nursing, Dessie Health Science College, Dessie, Ethiopia \\ ${ }^{2}$ Department of Medical Laboratory, Dessie Health Science College, Dessie, Ethiopia \\ Email address: \\ fikiralebachew@gmail.com (F. Alebachew),melakuashagrie@gmail.com (M. Ashagrie)
}

\section{To cite this article:}

Fikir Alebachew, Melaku Ashagrie. The Body-Image Concept Analysis of Youth and Adolescent. American Journal of Biomedical and Life Sciences. Vol. 5, No. 6, 2017, pp. 130-134. doi: 10.11648/j.ajbls.20170506.14

Received: October 16, 2016; Accepted: December 12, 2016; Published: November 28, 2017

\begin{abstract}
Body image is a complex entity, formed from both an Individual's mental representation of the integrity and competence of their own physical self, as well as their awareness of how others perceive them- the social interpretation of their physical self. This paper examined the concepts of body image and its relationship with Body image-dissatisfaction, physical self-concept and self-esteem. For Adolescents and Young Adults body image and its relation with the concept of physical self-image are very important because body image determines their relationship with their friends, their social activities, and their self-esteem. They are very hot and sensitive for everything. Also, they are productive groups than other groups. It has negative impact on their life. So, this concept analysis is very important to avoid the negative impact of it.
\end{abstract}

Keywords: Body Image Dissatisfaction, Physical Self-Concept, Self-Esteem

\section{Introduction}

Body image is a multidimensional construct describing an individual's mental representation of his or her own body. It is the mental image one holds for oneself, which includes perception and attitudes related to body and physical appearance $[1,4]$.

Body image is the total concept of conscious and unconscious feelings, thoughts, and perceptions. Changes in body image are particularly important in adolescence when attention is focused on appearance and attractiveness Body image dissatisfaction (BID) is conceptualized as the discrepancy between current and ideal body size estimates. Macro social factors such as the wealth or development level of a nation, household structure, religion, and relationship to globalization also systematically impact body image. The main ways in which body image relates to child well-being globally today are in terms of body image satisfaction or dissatisfaction, and the relationship of the latter to body image and eating disorders. In most parts of the world, body dissatisfaction has been found to be linked to potentially risky behavior such as disordered eating or body modification practices such as skin bleaching or plastic surgery.

\section{Definitions and Perspective of Body Image}

\subsection{Definitions of Body Image from Dictionaries}

The Oxford English Dictionary (OED) was used to explore the general definition of body image is the perception that the person has of their physical self and the thoughts and feelings that result from the perception These feelings can be positive,negative or both and are influenced by individuals and environmental factors.

\subsection{Philosophical Perspectives of Body Image}

Health Canada defines body image as "the picture an individual has of his or her body, what it looks like in the mirror, and what he or she thinks it looks like to others." (According to Eating Disorders Awareness and Prevention (EDAP), body image includes "how you feel in your body not just about your body". EDAP states that a person with "positive body image" has a true and clear perception of their 
body shape; celebrates and appreciates this shape, and understands that one's physical appearance says little about one's character and value as a person [3].

\subsection{Theoretical Perspectives of Body Image}

Media effects on body image concerns of young adult women in the U.S., there has been relatively little theoretically-driven research on processes and effects of social media on young women's body image and selfperceptions. Yet given the heavy online presence of young adults, particularly women, and their reliance on social media, it is important to appreciate ways that social media can influence perceptions of body image and body image disturbance.

\subsection{Use of the Concept of Body Image in Sociology}

Body Image a Sociological Analysis Sociology Essay the everyday lives of people living in the 21 st century are pervaded by the media. Due to the huge rise in modern technology the pressure on individuals to conform to a certain body type is more intense than ever. 'Repeated exposure to such images may lead a woman to internalize the thin ideal such that it becomes accepted by them as the reference point against which to judge themselves [9].

\subsection{Use of the Concept of Body Image in Professional Fields}

We have established that physical factors such as age, gender, pubertal maturation and timing are important aspects in children and adolescents' body image development.. However, there are also a number of socio-cultural factors that have been shown to impact the way that young people perceive their bodies and that, often influence them to develop a negative body image. Among the most influential social and cultural factors are macro social factors, media, toys, peers, and family.

\section{Distinguishing the Concept of Body Image from Other Closely}

\subsection{Related Concepts}

Body image dissatisfaction, Physical self-concept and Self-esteem. However, these concepts are not the concept of body image.

\subsection{Body-Image Dissatisfaction}

Body dissatisfaction also increases the likelihood that individuals engage in unhealthy body changing strategies such as excessive dieting and exercising, and the intake of body changing substances such as anabolic steroids. Particularly extreme examples are those who fall into eating disorders such as anorexia nervosa and bulimia nervosa. Anorexia nervosa is characterized by a refusal to maintain a minimally normal weight for age and height, an obsessive fear of gaining weight, and a distorted perception of one's body weight or shape [6].

\subsection{Physical Self-Concept}

Physical self-concept affects achievement of every individual.

This is an excerpt from Psychological Dynamics of Sport and Exercise. Physical Self-Concept focus on the specific domain of interest rather than on global self-concept,

\subsection{Self-Esteem}

Self-esteem reflects a person's overall subjective emotional evaluation of his or her own worth. It is a judgment of oneself as well as an attitude toward the self. Self-esteem encompasses beliefs (for example, "I am competent", "I am worthy") and emotions such as triumph, despair, pride, and shame [1]. Defined it by saying "The self- concept is what we think about the self; self-esteem, is the positive or negative evaluations of the self, as in how we feel about it."

\section{Determining Defining Attributes}

Defining attributes is to list the characteristics that are associated with a concept. Any Concept analysis will consist of more than one defining attribute; however, one needs to determine which attributes are appropriate for the purpose of exploration of the concept Based on this principle, the critical attributes of the concept of body image include:

\subsection{Constructing a Model Case}

As a child, Mr A was a healthy, social, interactive, and playful boy until, at age 5 years, he was hit by a runaway car. The accident led to a hospitalization for a clavicular fracture and facial trauma that resulted in a disfiguring scar on his right cheek. This scar led to teasing by his kindergarten classmates; he was nicknamed "scarface." As Mr A progressed through childhood and adolescence, he became quite shy and withdrawn; this prompted school teachers to place him in "special" classes. Although he never saw a mental health professional (eg, a psychologist, social worker, or psychiatrist), it was readily apparent that his shyness was exacerbated by interactions with his peers and that he cope up by withdrawing from social situations. Although his scar became less visible as he aged, his shyness persisted. Even as a young man, he was very uncomfortable having his picture taken or looking at his reflection. When someone stared at him, he felt that he was being ridiculed. However, if the looks and stares were accompanied by flattery, his discomfort would diminish. As an adult, Mr A was hospitalized for assessment of shortness of breath; there, he was the subject of morning rounds. Having all eyes focused on him made MrA feel self-conscious and criticized and he became less open in his responses and less willing to volunteer information that may have been helpful to his care. Despite a successful professional and personal life, his body image as an adult reflected his early response to trauma and disfigurement. 


\subsection{Analysis}

For Adolescents and Young Adults body image and its relation with the concept of physical self-image are very important because it determine their relationship with their friends, their social activities, and their self-esteem. They are very hot and sensitive for everything. Also, they are productive groups than other people groups. It has negative impact on their life. So, this concept analysis is very important to avoid the negative impact of it.

Body image involves perceptions, thoughts, and behaviors related to one's appearance. For example, Mr X's body image was dominated by having been a child with a scarred face. When a patient's world view or body image adversely impacts the provision of health care, primary care physicians should place such views in perspective and adjust care plans.

\section{Development of Additional Cases}

Additional cases may not involve the same concept as the model case but may be similar to the main concept or not in this paper, a borderline case and a contrary case are used to clarify the concept of the model case [8].

Contrary Case

A contrary case is the example which presents "not the concept." People can easily recognize this concept as not the main concept. At some point today; boys as young as 12 all over Britain will be pumping iron in gyms. They'll be doing it partly because their peers have convinced them that it's expected. Partly they'll be doing it because the gym is one of the few environments a young man in Britain can find unconditional acceptance and a sense of belonging [8].

Once enrolled at the gym, a typical boy will invariably be taken under the wing of one of the resident "personal trainers", usually a guy in his twenties, with the kind of muscular physique sported by the models in men's "health" magazines. The trainer prescribes the boy a punishing exercise regime, telling him it will make him "stronger". After a few weeks, when the endorphins have well and truly kicked in, giving the boy an addictive high, the trainer asks him if he'd like to be shown how to make his workout even more effective. After receiving the inevitable resounding "yes", the trainer will offer to sell the boy protein shakes, energy drinks, or, in the worst cases, anabolic steroids. What the boy doesn't know is that the trainer is on commission, a cog in a highly lucrative fitness industry that has made body image into a commodity. He doesn't care how much of these toxic and wholly unnecessary substances he has to push down the boy's throat - he wants to make a quick buck. Even if the boy is apprehensive about the dangers of steroids, he probably thinks protein shakes, energy drinks and whey powders are harmless enough. He's probably unaware that taken in excess protein shakes can cause liver failure, energy drinks can induce heart attacks and whey powders mimic estrogen in the body, so while Pecs grow larger, sperm count is reduced and infertility risked.

\section{Identifying Antecedents and Consequences}

\subsection{Antecedents}

These are the events or incidents that happen before the existing concept [8].

We have established that physical factors such as age, gender, pubertal maturation and timing are important aspects in children and adolescents' body image development. Another physical factor influencing body image development is body composition; however, there are also a number of socio cultural factors that have been shown to impact the way that young people perceive their bodies and that, often influence them to develop a negative body image. Among the most influential social and cultural factors are macro social factors, media, toys, peers, and family.

\subsection{Consequences}

When considering the consequences of negative body image, the problem of eating disorders typically comes to mind as one of the most serious. However, we should remember that body dissatisfaction, even when it does not lead to serious pathological outcomes like eating disorders, is a problem on its own, and unfortunately a very common one. It hinders many young people in their everyday lives, making them feel less comfortable with themselves and in their relationships with others. Some might refrain from showing themselves undressed among others in normative settings such as a locker room or avoid going to social events on days when they feel particularly dissatisfied. Others may be scared to speak their mind in groups, simply because they fear being looked at and evaluated by others on basis of their appearance. Research has shown that body dissatisfaction is connected to low self-esteem and decreased overall wellbeing. Longitudinal studies have shown that some individuals suffer from their body image concerns to such an extent that they develop depression, or even suicidal ideation [7].

Body dissatisfaction also increases the likelihood that individuals engage in unhealthy body changing strategies such as excessive dieting and exercising, and the intake of body changing substances such as anabolic steroids. Particularly extreme examples are those who fall into eating disorders such as anorexia nervosa and bulimia nervosa. Anorexia nervosa is characterized by a refusal to maintain a minimally normal weight for age and height, an obsessive fear of gaining weight, and a distorted perception of one's body weight or shape [6].

Bulimia nervosa is characterized by repeated episodes of binge eating followed by purging, fasting, or excessive exercise to compensate for the overeating.

\section{Defining Empirical Referents}

Body image is defined as an individual's attitude and perception regarding the physical self, and includes cognitions, affects, and behaviors "The evolution of psychological concepts about the body", Body Image, Development, 
deviance and change [4]

Body image is a complex entity, formed from both an Individual's mental representation of the integrity and competence of their own physical self, as well as their awareness of how others perceive them- the social interpretation of their physical self. Body image is widely recognized as an important psychosocial variable among individuals living with HIV/AIDS due to the variety of changes in physical appearance and bodily function resulting from illness and treatment. Body image were negatively related and appeared to influence unsafe sex, anal sex, and any sex in different ways. The concept of body image is complex, encompassing both individual's perception of self and the social interpretation of their body others body.

\section{Implication of Body Image Analysis for Nursing}

Which is successfully reduced both internalization of the thin ideal and perceptions of the realism of media image. Another intervention, the "everybody's Different" program, led to both short- and long-term self-esteem benefits, through focusing on positive self-appraisal around weight and body image. By extending or adapting the model presented here to even younger samples, it may be possible to provide a basis for theoretically informed educational programs that target girls before puberty and help prevent the decline in body image and self-esteem that currently is so typical of their middle adolescence.

\section{Conclusion}

Body image is a multi-faceted concept describing how people perceive, feel, and think about their bodies. Body image is a normative part of the process of growing up cross culturally and tends to be heavily gendered anywhere it has been studied. Individual, social, and cultural factors impact its development. Individual psychological makeup and individual body composition come into relationship with social and cultural factors through relationships with significant others such as parents and peers, and through shared experiences such as media and toys. At different times of the life cycle, these factors exhibit differential impact. For example, while mass media is important to shaping children's values and body images, media takes on heightened value during the developmental changes of adolescence. Macro social factors such as the wealth or development level of a nation, household structure, religion, and relationship to globalization also systematically impact body image. The main ways in which body image relates to child well-being globally today are in terms of body image satisfaction or dissatisfaction, and the relationship of the latter to body image and eating disorders. In most parts of the world, body dissatisfaction has been found to be linked to potentially risky behavior such as disordered eating or body modification practices such as skin bleaching or plastic surgery.

\section{References}

[1] Bolton MA, Pruzinsky T, Cash TF, et al. Measuring outcomes in plastic surgery: body image and quality of life in abdominoplasty patients. PlastReconstr Surg. 2003; 112(2): 619-625. discussion 626-627. [PubMed].

[2] Smolak L, Levine MP. Body image in children. In: Thompson JK, Smolak L, editors. Body mage, Eating Disorders, and Obesity in Youth: Assessment, Prevention, and Treatment. Washington, DC: American Psychological Association; 2001. pp. 41-66.

[3] (Malter AD, Emerson LL, Krieger)W: Attitudes of Washington State physicians toward health care reform. West J Med 1994; 161:29-33)

[4] Cash TF, Pruzinsky T, editors. Body Image: A Handbook of Theory, Research, and Clinical Practice. New York, NY: Guilford Press; 2004.

[5] Collins M. Body figure perceptions and preferences among pre-adolescent children. Int J Eat Disord. 1991; 10(2):191-208.

[6] Hildebrandt T,Walker C, Alfano L, Delinsky S, Bannon K, Development and Validation of a Male Specific Body Checking Questionnaire 2010 January; 43(1): 77-87. doi:10.1002/eat.20669.

[7] Thompson D, Obarzanek E,Franko D, Barton B, StriegelMoore, Childhood overweight and cardiovascular disease risk factors: The National Heart, Lung, and Blood Institute Growth and Health Study Pediatric. 2007 January; 150(1): 18-25.

[8] Walker, L., Avant, K. (1995) Strategies for Theory Construction in Nursing. 3rd ed. Appleton-Century-Crofts, Norwalk.

[9] Tiggemann M, Pennington B. The development of gender differences in body-size dissatisfaction. Australian Psychiatrist. 1990;25:301-311.

[10] Veron-Guidry S, Williamson DA. Development of a body image assessment procedure for children and preadolescents. Int J Eat Disord. 1996; 20(3): 287-293. [PubMed].

[11] Sands R, Tricker J, Sherman C, et al. Disordered eating patterns, body image, self-esteem, and physical activity in pre-adolescent school children. Int J Eat Disord. 1997; 21:151166. [PubMed].

[12] Childress A, Brewerton T, Hodges E, et al. The Kids' Eating Disorders Survey (KEDS): a study of middle school students. J Am Acad Child Psy. 1993; 32: 841-850. [PubMed].

[13] Graber JA, Peterson AC, Brooks-Gunn J. Pubertal processes: methods, measures, and models. In: Graber A, Brooks-Gunn J, Peterson AC, editors. Transitions Through Adolescence. Interpersonal Domains and Context. Mahwah, NJ: Erlbaum; 1996. pp. 23-53.

[14] Garner DM. Eating Disorder Inventory for Children (EDI-C) Odessa, FL: Psychological Assessment Resources; 1991.

[15] Mendelson BK, White DR. Relation between body-esteem and self-esteem of obese and normal children. Percept Mot Skills. 1982; 54(3): 899-905. [PubMed]. 
[16] Thelen M, Powell A, Lawrence C, et al. Eating and body image concerns among children. J Clin Child Psychol. 1992;21(1):41-46. 13. Mintz L, Betz N. Sex differences in the nature, realism, and correlates of body image. Sex Roles. 1986; 15(3-4): 185-195.

[17] Shisslak CM, Renger R, Sharpe T, et al. Development and evaluation of McKnight Risk Factor Survey for assessing potential risk and protective factors for disordered eating in pre- adolescent and adolescent girls. Int J Eat Disord. 1999; 25(2): 191-214. [PubMed].

[18] Williamson DA, Davis CJ, Bennett SM, et al. Development of a simple procedure for assessing body image disturbances. Behav Assess. 1989; 11: 433-446.

[19] Stunkard AJ, Sorenson TI, Schulsinger F. Use of the Danish Adoption Register for the study of obesity and thinness. In: Kety S, Rowland LP, Sidman RL, et al., editors. The Genetics of Neurological and Psychiatric Disorders. New York, NY: Raven Press; 1983. pp. 115-120. In. eds.

[20] Alleva JM, Sheeran P, Webb TL, Martijn C,Miles E (2015) A Meta-Analytic Review of Stand- Alone interventions to Improve Body Image. PLoS ONE 10(9): e0139177. doi: 10.1371/journal. pone.0139177.

[21] Asher SR, Wheeler VA. Children's loneliness: A comparison of rejected and neglected peer status. Journal of Consulting and Clinical Psychology. 1985; 53: 500-505. [PubMed: 4031205].

[22] Ata RN, Ludden AB, Lally MM. The effects of gender and family, friend, and media influences on eating behaviors and body image during adolescence. Journal of Youth and Adolescence. 2007; 36: 1024-1037.

[23] Barker ET, Bornstein MH. Global self-esteem, appearance satisfaction, and self-reported dieting in early adolescence. Journal of Early Adolescence. 2010; 30: 205-224. [PubMed: 23155302].

[24] Barnes GM, Windle M. Family factors in adolescent alcohol and drug abuse. Pediatrician. 1987; 14: 13-18. [PubMed: 3615298].

[25] Baumrind D. The influence of parenting style on adolescent competence and substance use. Journal of Early Adolescence. 1991; 11: 56-95.

[26] Bearman S, Presnell K, Martinez E, Stice E. The skinny on body dissatisfaction: A longitudinal study of adolescent girls and boys. Journal of Youth and Adolescence. 2006; 35: 217 229. [PubMed: 16912810].

[27] Cash TF. Body image attitudes: Evaluation, investment, and affect. Perceptual and Motor Skills. 1994; 78: 1168-1170. [PubMed: 7936939]. 